\title{
Alignment of Software Quality and Service Quality
}

\author{
Priit Parmakson \\ Institute of Informatics \\ Tallinn Technical University, Estonia
}

\begin{abstract}
Software is today an integral or even main component of various service systems. Therefore it is of interest to analyze how software quality is related to service quality. Due to somewhat different nature of services and software, but also due to historical reasons, software quality models and service quality models differ a lot at first look. In an example of widespread quality models in service management and software areas, it will be shown that substantial level of alignment can be reached between these models. However, these models use different languages and also contain quality attributes which can not be translated easily into language of other model. That gives reason for further elaboration of both quality models.
\end{abstract}

\section{Introduction}

Software is often a component (and frequently a main one) in a service system, though it is not common to view usage of software as service. When looking at existing models of software quality and service quality, we notice that these models differ remarkably. We will explore if a common ground can be found between quality models developed in two completely different research areas - software engineering and service management.

It would be good if software engineers could relate quality concepts they know well from software engineering to service aspects of their work. Indeed, the work of information system (IS) professionals is even more seen as service. At the same time, feedback from industry indicates that IS graduates are often weak in customer service skills. Insufficient service orientation of IS departments has been also frequently discussed (see, for example [21, 28]). Modern practice of IS development requires more experts who will be proficient in both developing a service (business) concept and building an information system.

\section{Concept of Service}

Meaning of the word 'service' has enlarged in recent times. Traditionally the service is understood as a process between human server(s) and human customer(s), where customer requires some transformation to be done by server. Though machines and software can be used as tools in traditional service, human-human interaction is dominant in this definition. A broader meaning of service does not assume that 
server is human. Instead, server can be a machine or software system (e.g. ATMs, electronic shopping systems, Internet services). According to this meaning, use of software is also use of service. Still broader meaning of the word 'service' does not even assume that customer is human. Instead, customer can also be a machine or technical system. That meaning is used in several ways in IS domain. For example, a telecommunications network provides services to applications, server offers services to client applications (client-server approach), an object has services (in objectoriented approach).

Due to some couple of dozen different sub-meanings of the word 'service', any widely applicable definition of service would have unavoidably an abstract nature. Some of the general definitions have been provided by Berry [1]: "Service is a deed, a performance, or an effort which is rendered by one party for another"; and Grönroos (cited in [12]): "A service is an activity or series of activities of more or less intangible nature that normally, but not necessarily, take place in interactions between the customer and the service employees and/or physical resources or goods and/or systems of the service provider, which are provided as solutions to customer problems."

\section{Software Systems are also Service Systems}

Pure service systems in a traditional sense (with dominating human-human communication) are becoming less common. The difference between manufacturing systems and service systems is also eroding. The product is more than a good, it is also the service package which delivers and maintains that good for the customer. Service becomes an integral part of the product. Pure service system, as well as pure information systems are abstractions - there are flows of material, information and humans in almost any process.

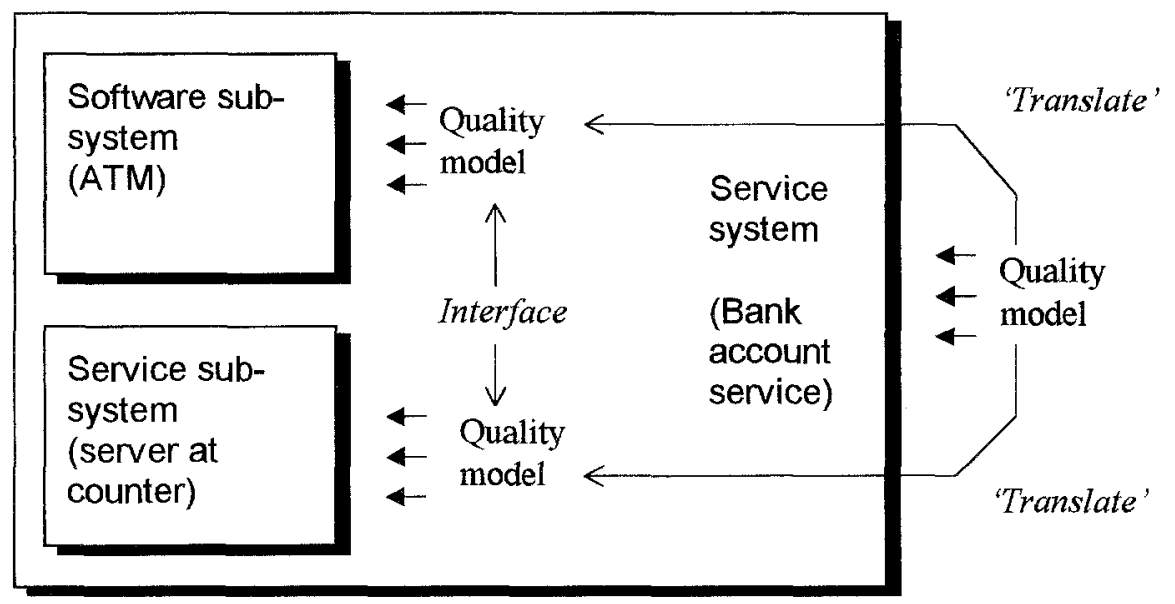

Fig 1. Aligning and interfacing quality models 
Software is commonly an element in a larger (computer-based) system, which includes also hardware, people, documentation, machines, procedures etc. (Fig. 1). The larger system can be a part of still larger system. Software requirements derive from system requirements. Purpose of quality of the software is to ensure quality of the encompassing service system. It is often said that system requirements must be translated (mapped) to requirements to system components (among these, to software). Quality Function Deployment is one of the methods which can be used to do this translation. Ideally, the business model of the company and the requirements model for the IS must be seamless [17]. However, if the language used to describe requirements at business level (quality of service system) and language used to describe requirements at system-component level (for example, quality of software component) differ principally, then the translation may be complicated and errorprone. Therefore it is desirable to align languages (models) of quality used for service systems and software systems.

Frequently a traditional human-human service system and a software-dominated service system work in parallel. For example, a bank customer can invoke transactions at ATM or at counter (served by human). Again, if the models used to analyze quality of automated service and non-automated service are radically different, then interfacing the two systems may be complicated.

\section{Structure of Quality Models}

Both in service quality and software quality, no better representations than attributebased have been devised for modeling quality. The general concept of quality is decomposed into number of quality attributes. Quality attributes are usually grouped into hierarchical structure, but more complex relationships between quality attributes have been used as well, mostly to represent synergy or conflict effects. Also, relative importance of attributes can be estimated.

Opinions differ about how to find appropriate quality attributes. Some researchers advocate a stable, general set of quality attributes while others emphasize tailoring the set of quality attributes to concrete situation. For example, the Critical Incident Technique [3] uses systematic elicitation of quality attributes hierarchy from a set of empirical service incident descriptions (both satisfactory and unsatisfactory incidents). Usefulness of the generic quality models is the underlying point here. Several authors tend to deny usefulness of generic service quality models, either explicitly or implicitly, by suggesting to elicitate customer requirements in each separate case. That means building the quality model from the scratch. According to this view, service systems are too different to get much help from a generic quality model. IEEE Standard for a Software Quality Metrics Methodology [14] also provides a list of quality attributes with reservation that the list is only an illustrative one. However, generic quality models could be useful to provide more elaborated frameworks than broad motivational guidelines of type 'customer is a king' [15]. Certainly the customer research provides important data, but it can not be assumed that all significant quality attributes can be extracted on the basis of customer input only. Customer research can also be expensive and require experienced analysts. 


\section{Software Quality Models}

Software quality can be defined as "the degree to which software possesses a desired combination of attributes" [14]. Several well-known software quality models (Boehm, McCall) consist of sets of quality attributes, which are structured into hierarchy. The model developed by ISO [16] uses three-level quality evaluation hierarchy: factors, criteria, metrics. On the highest level, the quality factors represent aggregate concepts. On the lowest level, the quality metrics can be given quantitative or qualitative values. Criteria are refinements of factors. The model proposed in IEEE standard [14] has six upper-level quality attributes (factors):

- Functionality

- Reliability (Does the system behave accurately all the time?)

- Usability (Is the system easy to learn and use?)

- Efficiency (The amount of resources required by the system to perform its function)

- Maintainability (Is it easy to find and fix an error in a system? Is is easy to enhance the system?)

- Portability (Is it easy to transfer the system from one environment to another?).

Though each of the software quality models proposed up to now has a somewhat different set of quality attributes, the differences are not large and the models follow well a common, established ideology.

\section{Service Quality Models}

Service quality has been a widely discussed concept. Four mainstream definitions of quality have been: quality as an excellence, value to customer, conformance to specifications, meeting and exceeding customer expectations [23]. Nevertheless, more extended and deeper definitions of quality have seen sought for recently: "Quality isn 't something you lay on top of subjects and objects like tinsel on a Christmas tree" [22]. We will build our discussion on the following understanding of service quality (Fig. 2): Service quality is a fit between service provider's process and customer's process, but also between other, related processes.

This definition is in accord with several recently developed viewpoints to service quality:

- Process view of the customer relationship [27] - the relationship consists of interactions which may have different content, frequency, duration etc. Interactions between server and customer are analyzed from a long-term point of view. Both parties of the relationship are engaged in their own processes as well (the provider's process and the customer's process).

- Extension of the concept of quality to cover all stakeholders of the firm. Achieving customer satisfaction is an admirable goal, but a firm is also responsible to multiple sets of stakeholders (owners, personnel, customers, suppliers, 
authorities etc), each of whose evaluates the firm on different criteria $[10,13$, $18]$.

- Partnership. The claim "Customer is always right" is a too strong abstraction, because: (a) limitless adaptation to customer expectations drives costs (a satisfied customer is not inevitably a profitable customer); (b) customers may simply not know what is possible (R.Normann cited in [27]). Therefore, adaptation must occur from both service provider's and customer's side. Note that Figure 2 is symmetric. Indeed, customers may depend on service provider as well (for example, due to high switching costs). It makes sense to talk also about requirements to customer.

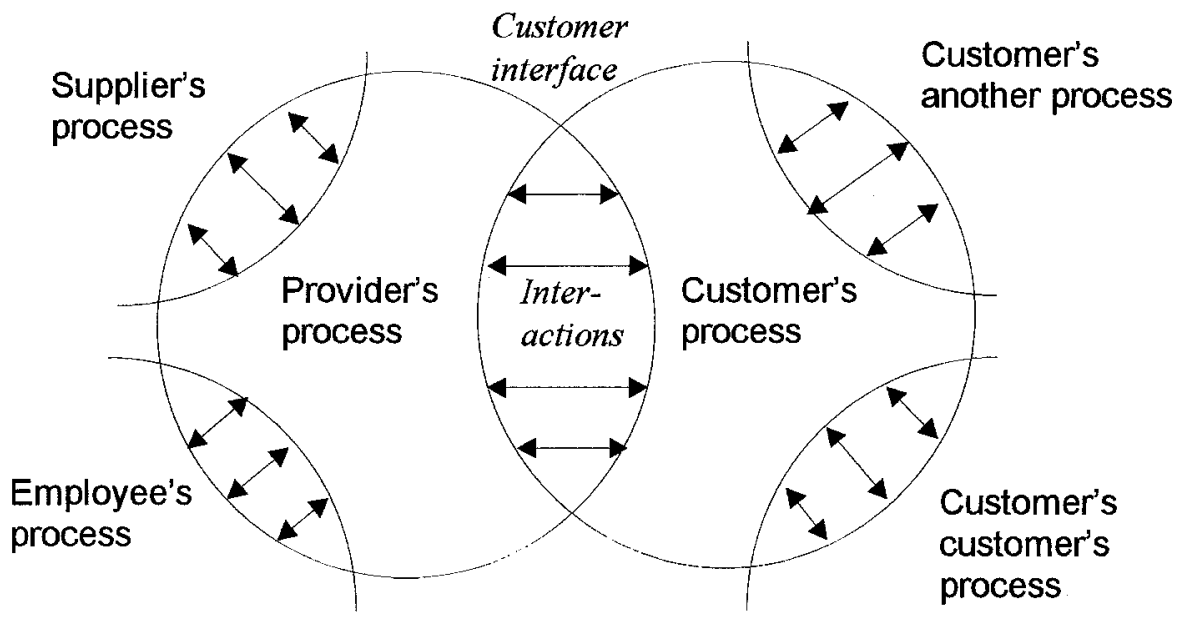

Fig 2. Processes involved in service

Direct consequences from the definition above are: (a) it is not enough to ask customer to state his needs - both customer and server processes must be understood and modelled at appropriate level of detail; (b) one must also look how provider's process and customer's process are fitted to other processes. Output from the service process is really only the input to customer's other processes.

Some of the most well-known generic service quality models are SERVQUAL [29] and Grönroos' model [8]. Based on empirical data, Zeithaml et al have identified ten general criteria most used by customers in judging service quality (Fig. 3). While in software quality domain the set of quality attributes is quite stable, service quality models vary considerably more. For example, Figure 3 depicts some relationships between SERVQUAL and a service quality model proposed by Gilmore and Carson [7]. 
- Tangibles (appearance of physical facilities, equipment, personnel and communication materials)

- Reliability (ability to perform the promised service dependably and accurately)

- Responsiveness (willingness to help customers and provide prompt service)

- Competence (possession of the required skills and knowledge to perform the service)

- Courtesy (politeness, respect, consideration, and friendliness of contact personnel)

- Credibility (trustworthiness, believability, honesty of the service provider)

- Security (freedom from danger, risk or doubt)

- Access (approachability and ease of contact)

- Communication (keeping customers informed in language they can understand and listening to them)
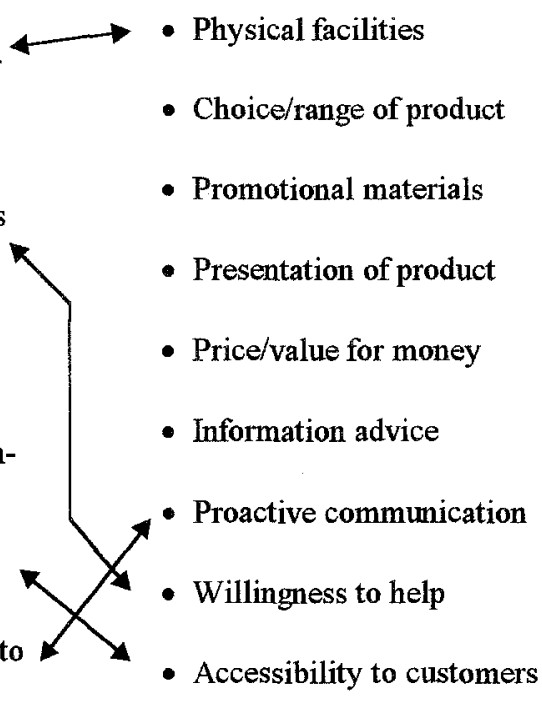

- Understanding the Customer (making the effort to know customers and their needs)

Fig 3. Two general service quality models

Note that the quality attributes in these general quality models are quite different from attributes used in software quality models. However, if the service system contains software then the software quality requirements must be derived from service quality requirements.

\section{Aligning Software Quality Model with Service Quality Model}

Next we try to relate service quality attributes to software quality attributes (Fig. 4). Quality attributes of the SERVQUAL model appear on the left, while the right column provides a list of software quality attributes, which is compiled on basis of the documents [14] and [16]. SERVQUAL is a representative service quality model despite of some recent criticism, it has had most influence during the last decade. Note that only two quality attributes bear exactly the same names in both models (Reliability and Security). Five service quality attributes (Responsiveness, Credibility, Access, Communication, Understanding the Customer) can be partly translated into one or more software quality attributes. Both models contain also attributes for which there are no analogies in other model. Thus the alignment between two models is not complete. 
SERVQUAL service quality model [29]
A software quality model.

Source: $[14,16]$

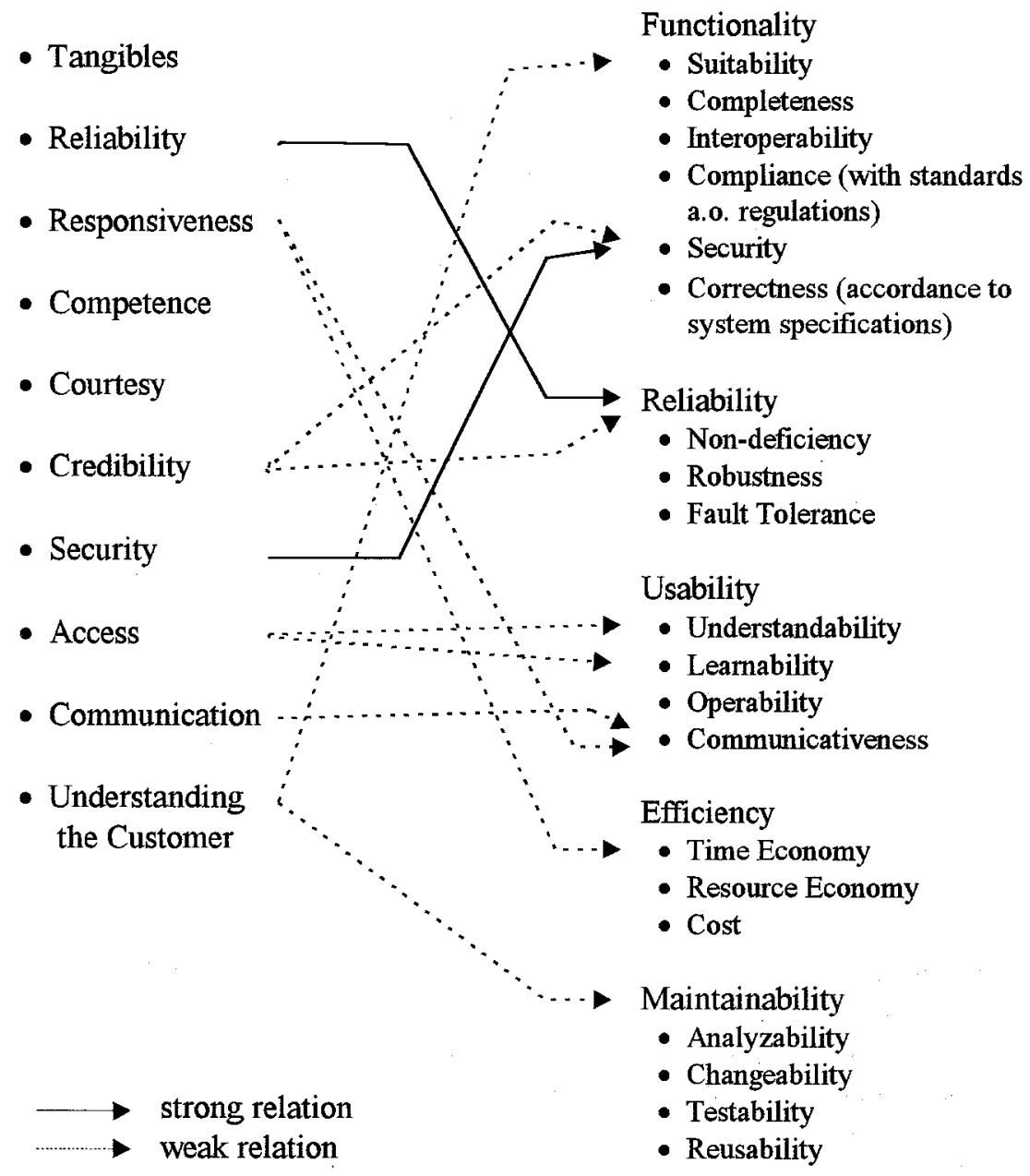

Fig 4. Relations between attributes of service quality and software quality

\section{Reasons for non-alignment}

The most interesting observation from the comparison above is that in software quality models there are no analogies to Courtesy. In principle, Courtesy may be related to Security, Communicativeness and Cost (courtesy gives the customer a feel- 
ing of security and helps to make communication more open; also, customers are not willing to pay a psychological cost related due to arrogant servers). These relations look however quite artificial. Reason may lay in social dimension that is much more explicit and important in human-human interaction than in human-computer interaction.

The languages used in the models compared above are quite different. That may be caused by different historical backgrounds of the fields. Service management has traditionally dealt with human-human interaction, though the concept of service has enlarged continuously. Therefore the service quality attributes are frequently expressed in terms more common to human-human interaction. Software engineering has technical roots and service concepts have been only slowly gained influence in this field. As it is still uncommon to view usage of software as service, the language used in software quality models is more technology-related.

Another reason for non-alignment seems to hide in mixed use of quality attributes of different types in service quality models. The discussion here will benefit from distinction of functional/non-functional, 'what'/ 'how' and core/cue attributes.

Functional and non-functional quality attributes. Distinction of functional and non-functional quality attributes (and accordingly - requirements) seems to be more common in software than in services. Functional requirements are those specific to the system, while non-functional requirements are 'additional' in the sense that these are common for all systems and may be usually assumed. Non-functional requirements may also be regarded as constraints to the functional requirements. Of course, distinction between functional and non-functional criteria depends on point of view non-functional requirements (e.g. security) can be dealt explicitly as functions of the system.

Courtesy seems to be a non-functional service quality attribute. Social dimension is present in any human-human interaction, and indirectly also in human-computer interaction. Courtesy may be a functional quality attribute if the customer is ready to pay for additional psycho-social benefits acquired due to higher than usual courtesy. Should a software service system show respect towards customer and how? Respect to user is not an issue in home-made small software programs, but certainly it is a problem in many large information systems. An intelligent software system must be able to be courteous. We suggest to consider adding Courtesy to software quality models.

'What' and 'how' quality attributes. It is a good practice in IS requirements engineering to separate 'what' and 'how' requirements. An analogous thinking is useful for quality attributes in general. Some attributes are part of the problem while other attributes are part of the solution. Differences in quality models may be explained partly by the fact that one model can include solution-oriented attributes while another model can emphasize underlying, basic attributes. SERVQUAL seems to contain three 'how' attributes: Tangibles, Competence and Understanding the Customer. Indeed, customers are rarely interested in tangibles and competence per se.

Core and cue attributes. Customers are judging service frequently on service cues ('little things' or supplemental services). That is because: (a) customers may assume that the core offering will be of high quality; (b) typically there is little variability in 
the core offerings; (c) core quality attributes of the service may be hard to judge [13]. Quality cues are what the customer observes (price, brand name, country of origin, store name), and core quality attributes are what the consumer wants. Often the true state of a quality attribute cannot be observed by the individual, but must be inferred through the cues [26]. SERVQUAL also seems to contain one cue attribute - Credibility. The core/cue distinction looks new to software quality.

\section{Service management and software engineering: exchange of knowledge and methods}

Manufacturing quality management seems to be more deeply developed than service quality management $[5,11]$. Indeed, several quality tools and methods which have originated in manufacturing, have been recently applied or proposed to be applied to service processes (for example, application of robustness concept to service processes [25]; application of poka-yoke, or fail-safe methods in services [6]). As for opposite example, O'Hara and Frodey [10] transferred a model developed for evaluating service success to manufacturing. Similarly, we expect to see a transfer of methods and concepts from IS/software engineering field to services as well.

Concept of service has enlarged and complexity of service systems has grown. Despite that, public discussion about service quality relies largely on psychological and cultural points of view. Services can and should be analyzed from different points of view. cultural, psychological, economic, management, organization theory, information systems theory, social etc. Customer service can be viewed even as a performing art [30]. Service systems should be analyzed also both in macro-level (in context of business environment) and micro-level (single service transaction). Models and methods which pretend to comprehensive treatment of services should be therefore multi-disciplinary. Service management is seen as not yet a coherent research area [9]. Therefore it is natural that different disciplines impact the service management perspective. IS development methodologies which seek to integrate service analysis and IS design are still rare, for example a SPITS methodology (Strategic Planning of IT Services) [19]. As more system thinking approaches to service quality are being called for $[2,24]$, we expect more ideas and concepts to be transferred from IS/software engineering field to service management. Recent developments in business modelling [17] and enterprise modelling [4] are examples of how system analysis methods diffuse into business management domain. It seems also probable that some convergence will occur between IS usability analysis and service usability analysis.

Though services are becoming more knowledge- and information-intensive [20], IS developers often treat service quality as not being within their range of competence. The result will be poor match between service quality models specified by service management specialists and software quality models developed by system analysts. 


\section{Conclusion}

Although this exploratory study has found the correspondence between widespread models of service quality and software quality to be incomplete, both service management and software engineering can benefit by widening and re-interpreting their quality languages.

\section{References}

1. Berry L.L. (1984) Services Marketing is Different. In: Lovelock (ed.), Services Marketing. Prentice-Hall.

2. Bitran G., Lojo M. (1993) A Framework for Analyzing the Quality of the Customer Interface. European Management Journal, 11, 4, 385-396.

3. Bitner M.J., Booms B.H., Tetreault M.S. (1990) The Service Encounter: Diagnosing Favorable and Unfavorable Incidents. Journal of Marketing, 54, 1, 71-84.

4. Bubenko J.A. et al (1992) Computer Support for Enterprise Modelling and Requirements Acquisition. Esprit III Project 6612: Deliverable 3-1-3-R 1 Part B.

5. Cavaness J.P., Manoochehri G.H. (1993) Building Quality into Services. SAM Advanced Management Journal, 1, 4-8.

6. Chase R.B., Stewart D.M. (1994) Make Your Service Fail-Safe. Sloan Management Review, 2, 35- 44.

7. Gilmore A., Carson D. (1993) Quality Improvement in a Services Marketing Context. Journal of Services Marketing, 7, 3, 59-71.

8. Grönroos C. (1984) A Service Quality Model and Its Marketing Implications. European Journal of Marketing, 18, 4, 36-44.

9. Grönroos C. (1994) From Scientific Management to Service Management. International Journal of Service Industry Management, 5, 1, 5-20.

10. O'Hara J., Frodey C.A. (1993) A Service Quality Model for Manufacturing. Management Decision, 31, 8, 46-51.

11. Henkoff R. (1994) Service is Everybody's Business. Fortune, June 27.

12. Holmlund M., Kock S. (1992) Quality-based Service as an Establishing Strategy in Business Networks. Working Paper No. 249, Swedish School of Economics and Business Administration, Helsinki.

13. Iacobucci D., Grayson K., Ostrom A. (1994) Customer Satisfaction Fables. Sloan Management Review, 2, 93-96.

14. IEEE (1992) Standard for a Software Quality Metrics Methodology. IEEE Std 1061-1992. Institute of Electrical and Electronics Engineers.

15. Iivari J., Koskela E. (1987) The PIOCO Model for Information Systems Design. MIS Quarterly, 401-419.

16. ISO (1988). ISO/IEC JTC1/SC7/WG3. Software Quality Evaluation. Software Quality Metrics. Working document. International Standardization Organization.

17. Jacobson I., Ericsson M., Jacobson A. (1995) The Object Advantage. AddisonWesley. 
18. Kankkunen K. (1993) Broadening the Concept of Quality: a Systems Model of Quality and Stakeholder Satisfaction. PhD Diss. Tampere University of Techology, Finland.

19. Leppanen M., Lyytinen K., Halttunen V. (1992) Tietojenkasittelystrategian maarittely. Strateginen tietohallintopalveluiden kehittamismenetelma (SPITS). University of Jyvaskyla, Finland.

20. Mattsson J. (1994) Improving Service Quality in Person-to-Person Encounters: Integrating Findings from a Multi-disciplinary Review. The Service Industries Journal, 14, 1, 45-61.

21. Ouellette L.P. (1994) A Formula for IS Service. Journal of Systems Management. 1, 34-35.

22. Pflaum P.E. (1994) Personal communication.

23. Reeves C.A., Bednar D.A. (1994) Defining Quality: Alternatives and Implications. Academy of Management Review, 19, 3, 419-445.

24. Ronkko, M. (1994) Palvelujen tunnusluvut. Hallinnon tutkimus, 1, 67-71.

25. Snee R.D. (1993) Creating Robust Work Processes. Quality Progress, 2, 37-41.

26. Steenkamp J-B.E. (1990) Conceptual Model of the Quality Perception Process. Journal of Business Research, 21, 309-333.

27. Storbacka K. (1993) Customer Relationship Profitability in Retail Banking. Swedish School of Economics and Business Administration, Helsinki.

28. Watson R.T. et al. (1993) User Satisfaction and Service Quality of the IS Department: Closing the Gaps. Journal of Information Technology, 8, 257-265.

29. Zeitham1 V.A., Parasuraman A., Berry L.L. (1990) Delivering Quality Service. Balancing Customer Perceptions and Expectations. The Free Press.

30. Zemke R. (1993) Customer Service as a Performing Art. Training, 3, 40-44. 